\title{
An intravenous organophosphate poisoning with intermediate syndrome: An unusual way of intoxication
}

\author{
Ashok Badhe, S. Sudhakar
}

Organophosphate (OP) poisoning is very common form of poisoning in Indian population because of its
availability and easy access. Intoxication occurs following the absorption of OP agents through gastrointestinal
tract, skin and respiratory tract and rarely by intramuscular or intravenous route. The clinical features depend
on the amount of the poison consumed, it's concentration, the route of administration and the time of
instituting therapy. We are reporting a case of an intravenous monochrotophos poisoning, an unusual way
of intoxication, which was managed in our ICU.

Key words: IV organophosphate, intermediate syndrome

\section{Case Report}

A 32-year-old male, accidentally received $4 \mathrm{ml}$ of $38 \%$ water soluble content (WSC) monochrotophos by intravenous route. He had developed signs and symptoms of cholinergic crisis with in 30 min of injection and was admitted in our ICU for ventilatory support. He had developed severe respiratory distress with paradoxical breathing and hemodynamic instability. He was intubated and ventilatory support was instituted. He received atropine loading dose followed by continuous infusion and pralidoxime. Pralidoxime and atropine was continued for 5 days. Lower respiratory tract infection was managed with appropriate antibiotics. Ventilatory parameters were adjusted according to blood gas analysis at regular intervals. He required full ventilatory support for first 5 days and then was gradually weaned off from ventilatory support. He improved symptomatically

\section{From:}

Department of Anaesthesiology and Critical Care, Jawaharlal Institute of Post Graduate Medical Education and Research, Pondicherry, India

Correspondence:

Prof. Ashok Badhe, Type-V/5, JIPMER, Pondicherry, India.

E-mail: ashokbadhe@hotmail.com after 8 days of intensive therapy and was on T piece trial for few hours on day nine before extubation. But he developed features of intermediate syndrome like proximal limb weakness, worsening of ophthalmoplegia, depressed deep tendon reflexes, etc., and required full ventilatory support. Pralidoxime was restarted and administered for next 5 days.

Tracheostomy was done on day 10 and he was weaned off from the ventilatory support gradually over a period of 1 week. Tracheal decanulation was done on day 19 and he was shifted to general ward for further management and later discharged.

\section{Discussion}

Acetylcholine acts as neurotransmitter in both sympathetic and parasympathetic ganglia and is hydrolyzed into choline and acetic acid by true and pseudocholinesterases. Organophosphate (OP) agents irreversibly inhibit choline esterase activity, which leads to accumulation of acetylcholine at the synapse. This leads to both nicotinic and muscarinic symptoms like 
nausea, vomiting, excessive salivation, urination, lacrimation, tracheobronchial secretions, skeletal muscle weakness, miosis, bradycardia and hypotension or hypertension. The severity of symptoms depend on percentage and the amount of poison consumed. ${ }^{[1-3]}$

In this case, the patient received $4 \mathrm{ml}$ of $38 \%$ (WSC) monochrotophos intravenously. He developed cholinergic crisis within $30 \mathrm{~min}$ and had respiratory distress and required full ventilatory support. Atropine infusion and pralidoxime was administered immediately after admission to the ICU. The patient developed intermediate syndrome even though we administered pralidoxime within $6 \mathrm{~h}$ of consumption of poison, which might be due to inadequate plasma concentration of pralidoxime, which leads to persistent inhibition of choline esterase activity. ${ }^{[3]}$ In this case we administered pralidoxime as intermittent boluses as per our ICU protocol. Administration of pralidoxime as continuous infusion at a rate of $4-8 \mathrm{mg} /$ $\mathrm{kg} / \mathrm{h}$ might be effective way to achieve satisfactory plasma level $\left(4 \mathrm{mg} / \mathrm{l}^{[2]}\right.$ in order to reverse the cholinergic crisis. There are few studies, which show administration of pralidoxime as continuous infusion is more effective than as intermittent boluses. ${ }^{[1]}$

There are very few case reports of parenteral OP poisoning. Guven et al. ${ }^{[4]}$ have reported an intravenous methamidophos poisoning case, who developed features of acute cholinergic crisis within $30 \mathrm{~min}$ and had satisfactory recovery with intermittent boluses of Pralidoxime. Zoppellari et al. ${ }^{[5]}$ reported a case of 80year old man who was injected Isofenphos by intramuscular route (in the thigh). He developed cholinergic crisis $5 \mathrm{~h}$ after injection and the signs and symptoms lasted for 3 weeks probably due to slow release of OP agent into the circulation and he required prolonged pralidoxime therapy.

According to our knowledge this may be the first case of intravenous OP poisoning, which had developed intermediate syndrome. We are reporting this case to cite that Intravenous OP poisoning can also result in intermediate syndrome in spite of immediate treatment.

\section{References}

1. Namba T, Nolte CT, Jackrel J, Grob D. Poisoning due to organophosphate insecticides. Acute and chronic manifestations. Am J Med 1971;50:475-92.

2. Aaron CK. Organophosphates and Carbamates. In: Ford MD, Delaney KA, Ling LJ, Erickson T, editors. Clinical Toxicology. $1^{\text {st }}$ ed. W.B. Saunders Co: 2001. p. 820-6.

3. Ellenhorn MJ. Pesticides. In: Ellenhorn MJ, Schonwald S, Ordog G, Wasserberger J, editors. Diagnosis and treatment of Human poisoning. $2^{\text {nd }}$ ed. Williams and Wilkins: 1997. p. 1617-20.

4. Guven M, Unluhizarci K, Goktas Z, Kurtoglu S. Intravenous organophosphate injection: An unusual way of intoxication. Hum Exp Toxicol 1997;16:279-80.

5. Zoppellari R, Borron SW, Chieregato A, Targa L, Scaroni I, Zatelli R. Isofenphos poisoning: Prolonged intoxication after intramuscular injection. J Toxicol Clin Toxicol 1997;35:401-4.

Source of Support: Nil, Conflict of Interest: None declared. 